\title{
Feministas e Ceramistas: Mulheres Artistas da Cena Contemporânea Latino Americana
}

\author{
Feministas y Ceramistas: Mujeres Artistas de la Escena Contemporánea \\ Latinoamericana
}

\author{
Feminists and Ceramists: Women Artists of the Contemporary Latin \\ American Scene
}

\author{
Flavia Leme de Almeida ${ }^{1}$
}

\begin{abstract}
Resumo
O presente artigo tem como objeto evidenciar a produção artística de três mulheres artistas latino-americanas da cena contemporânea por meio de um recorte temático balizado nas questões que tangenciam o que se pode chamar de arte feminista. Para tanto, foi necessário anteriormente contextualizar a cerâmica enquanto suporte recorrente na arte contemporânea, apesar do seu histórico ligado ao utilitário e ao artesanato. Na mesma medida em que foi necessário contextualizá-la no prisma sociopolítico latino americano. Utilizou-se como método de pesquisa a revisão bibliográfica e a análise de parte das produções artísticas das seguintes mulheres artistas: Celeida Tostes (Brasil), Kukuli Velardi (Peru) e Rubie Rumy (Colômbia). Como considerações finais observouse após analise que as obra das artistas supracitadas tem em comum uma vasta produção artística que não se limita apenas na utilização da cerâmica como suporte artístico, que se valem de instalações com objetos seriados e que algumas vezes necessitam da participação de outras pessoas para realizarem seus trabalhos.
\end{abstract}

Palavras-Chave: Arte Contemporânea; Cerâmica; Feminismo; América Latina.

\section{Resumen}

Este artículo tiene como objetivo destacar la producción artística de tres artistas latinoamericanas de la escena contemporánea a través de un recorte temático basado en las preguntas que tocan lo que se puede llamar arte feminista. Por lo tanto, se fue necesario contextualizar la cerámica como un soporte recurrente en el arte contemporáneo, a pesar de su historia vinculada a utilitarios y artesanías. En la misma medida, se fue necesario contextualizarlo en el prisma sociopolítico latinoamericano. La revisión bibliográfica y el análisis de parte de las producciones artísticas de las siguientes artistas fueron utilizadas como método de investigación: Celeida Tostes (Brasil), Kukuli Velardi (Perú) y Rubie Rumy (Colombia). Como consideraciones finales, después de analizar las obras de los artistas antes mencionados, se observó que esas tienen en común una vasta producción artística que no se limita solo al uso de la cerámica como soporte artístico, pero también se utilizan instalaciones con objetos en serie y que a veces requieren la participación de otras personas para hacer su trabajo.

Palabras claves: Arte Contemporáneo; Cerámica; Feminismo; Latino Americano.

\begin{abstract}
The main purpose of this research is to highlight the artistic production of three Latin American women artists from the contemporary scene through a thematic cutout based on the questions that touch what can be called

1

Doutora em Artes Visuais pela Linha de Pesquisa Processos e Procedimentos Artísticos pelo Instituto de Artes da UNESP; Professora no Departamento de Disciplinas Tridimensionais e Artes Visuais da Escola Guignard; Belo Horizonte, Minas Gerais, Brasil; flalemeal@gmail.com.
\end{abstract}


feminist art. Therefore, it was necessary to contextualize ceramics its recurrence as support in contemporary art, putting aside ceramics history as utilitarian and as crafts. To the same extent that it was necessary to contextualize ceramics within the Latin American socio-political framework. As a research method, we conducted a literature review and an analysis of the artistic production of the following artists: Celeida Tostes (Brazil), Kukuli Velardi (Peru) e Rubie Rumy (Colombia). After the analysis of the aforementioned artists, we observed that their artistic production is vast and not limited only to the use of ceramics as artistic support, but they make use of serialized objects and sometimes require others' help to execute their works.

Keywords: Ceramics; Contemporary art; Feminism; Latin American

De certo que existe um questionamento para todo artista ceramista da atualidade: mas, afinal, qual é o papel da cerâmica dentro do contexto da arte contemporânea, já que este é um material que coexiste com a civilização humana desde tempos remotos e ainda se faz presente de inúmeras formas no cotidiano das pessoas? Com um histórico de origem utilitária, a cerâmica esteve e ainda está ligada às artes aplicadas, à manufatura e ao artesanato de modo como se entende na contemporaneidade. No texto $O$ uso e a contemplação, Octavio Paz (2006) discorre sobre a relação entre os objetos e as pessoas, sob o ponto de vista da relação entre a beleza, o design e sua função/utilidade, relacionando a forma, ou seja, a maneira como esses objetos foram fabricados, com sua função, o motivo e a finalidade para o qual eles foram feitos. Os objetos de uso cotidiano englobavam em si uma força e uma beleza que transbordavam do seu mero significado útil: um jarro grego de barro continha, além de sua função de conter líquidos, um formato harmônico e proporcional. É realmente deveras complicado analisar esses objetos sob a perspectiva deslocada de seu contexto histórico e significado original, sendo vistos atualmente como objetos de arte em museus. Este artigo, portanto, não pretende colocar em xeque valores de juízo com relação à qualidade estética de determinadas obras de arte, artesanato ou design. Vale lembrar que, dentro da história, existem inúmeros exemplos de objetos entendidos como artesanais, dentro da ótica ocidental, que serviram de inspiração e de influência para os modernistas europeus. Isto posto, destacase aqui que a cerâmica é, contraditória e simultaneamente, arcaica e contemporânea, já que caminha em paralelo com a história e os desenvolvimentos social, artístico e cultural da humanidade.

E se ao se direcionar para a cerâmica arqueológica dos diversos povos originários das Américas, se observa que nela havia características tão distintas quanto as culturas das quais pertenciam. Fruto de séculos de violentas e impostas misturas, influências culturais, opressões políticas e sociais, o povo latino-americano e, consequentemente, o produto de sua arte, tornou-se algo que se pode definir como uma "mestiçagem mutante", já que apenas "mestiça" acaba por ser insuficiente para ilustrar as inúmeras camadas e nuances oriundas da mistura 
entre os povos originários, com os estrangeiros europeus, africanos e asiáticos. Subjetividades complexas e ambíguas, profusas identidades fragmentadas podem definir melhor o conjunto das nações que atualmente formam a América Latina.

Mais recentemente na história da civilização, os dois últimos séculos foram marcados por significativas transformações mundiais em vários âmbitos, sobretudo o tecnológico. Isso, obviamente, se desdobra e reflete no modo como se pensa e se produz arte. O mundo atual tornou-se mais conectado: o frescor que o Novo Mundo trouxe ao Velho esvaneceu-se já que tudo pode ser acessado em um piscar de olhos e estalar de dedos. Serra e Escobar (2005, p.162) observam que a globalização trouxe contraditórias intervenções: ao mesmo tempo em que evidenciou as diversidades e diferenças, as ameaçou, uma vez que homogeneizou e pasteurizou a cultura. Ainda que haja encontros e discussões sobre os problemas relativos ao ecossistema no mundo, temas ligados à cultura e à arte, desigualdades sociais e econômicas, corrupção ou violência, fomentados nessa "ágora virtual transitória", mostrando modelos de cidadania transnacional, horizontais e descentralizados, ainda sim são políticas alternativas, não reativas, mantendo a utopia (como um não lugar) dentro de um panorama desencantado. Nas pontuais palavras de Eduardo Galeano "A igualação, que nos uniformiza e nos apalerma, não pode ser medida. Não há computador capaz de registrar os crimes cotidianos que a indústria da cultura de massas comete contra o arco-íris humano [...].” (GALEANO, 2015, p. 32).

Concomitantemente à essas mutações sociopolíticas econômicas mundiais surgiram as chamadas ondas feministas ${ }^{2}$. Desde a segunda onda do movimento feminista diversos estudos sobre a questão do feminismo nas artes visuais vêm sendo desenvolvidos: muitas pesquisadoras e historiadoras de arte levantaram indagações acerca daquilo que podemos chamar de uma arte feminista feita por mulheres. Segundo Garcia (2015), foi utilizado pela primeira vez o termo "feminismo" nos Estados Unidos, em 1911, por intelectuais de ambos os sexos para fazerem referência às questões e aos problemas referentes às mulheres. Tinha como meta, além do sufrágio, equilibrar as relações e as necessidades de âmbitos profissional, pessoal, individual e política das mulheres, coisa distante de se conseguir. Assim, da mesma forma que o feminismo é a conscientização "das mulheres como coletivo humano, da

\footnotetext{
${ }^{2}$ De acordo com certa vertente, o feminismo divide-se em três momentos de manifestação na história: a primeira onda, ou feminismo moderno, marcado pela obra de Poulain de La Barre e o movimento de mulheres da Revolução Francesa no século XVIII; a segunda onda, que ressurge simultaneamente com outros movimentos sociais do século XIX, como as sufragistas e a terceira onda, ou feminismo contemporâneo, que surge após a revolução sexista dos anos 1960/70 e as novas tendências nascidas no final do anos de 1980. (GARCIA, 2015, p. 24)
} 
opressão, dominação e exploração de que foram e são objeto por parte do coletivo de homens [...] e se articula como filosofia política e, ao mesmo tempo, como movimento social" (GARCIA, 2015, p.13) também o é no caso de uma arte politicamente engajada nas questões que concernem as mulheres na sociedade: atitudes que negam os discursos machistas e sexistas, que só fazem reafirmar o ideal de superioridade e universalidade do homem em detrimento da mulher. Como exemplo, basta observar que a palavra homem é também usada para se referir à espécie humana, por exemplo. Quando se coloca o homem como medida de todas as coisas (vide o Homem Vitruviano, que se tornou célebre pela representação feita por Leonardo Da Vinci), colocando a perspectiva masculina como válida para todo restante do mundo, universalizando-a, dá-se o nome de androcentrismo. Quando em 1949 Simone de Beauvoir afirmou em seu famigerado livro O Segundo Sexo, que para ser uma mulher era preciso que se tornasse uma, não bastando, portanto, nascer com a genitália feminina, ela pontuou que o conceito sobre o feminino era uma construção cultural imposta por meio de regras, padrões, legislações, normas de ensino e educação - tanto no âmbito público quanto e especialmente no âmbito privado - que ditam como deve ser e se comportar uma mulher socialmente. Regulada por uma sociedade dominada pelo patriarcado, a mulher tornava-se "o outro" do sujeito homem: ela apresenta-se em assimetria ao homem e precisa ser ratificada a todo o momento por ele, conceito este que Beauvoir chamaria de heterodesignação. De fato, observa-se que, mesmo hoje, valores como a virilidade, o fálico e o dominante estão ligados ao masculino, e o indefinível, a sensível e a vulnerável, ao feminino. Beauvoir descreveu que, dentro da ótica tradicional, a fisiologia feminina - os ciclos menstruais, menopausa, climatério, maternidade - era apontada como sendo uma característica inferiorizante, visto que delimitava e muitas vezes incapacitava a mulher (THEBAUD in DUBY; PERROT, 1991, p. 343). Ocorre que não foi permitido às mulheres terem o mesmo status quo que os homens e isso não apenas nas artes, mas em centenas de outras áreas, como a política, as ciências, por exemplo. O mundo como estava estruturado, com seus símbolos, signos, sinais, o sistema educacional, o mercado de trabalho, fazia com que, em situações adversas quando uma mulher artista se destacasse, fosse tido como algo excepcional, muito fora do comum. Há ainda vertentes de pesquisadoras que identificaram inúmeras mulheres artistas que tiveram papéis relevantes na história da arte, que foram, por diversos motivos, ignoradas pelos críticos e historiadores de arte. Deve-se atentar que, durante a maior parte do tempo, a história foi escrita pelos dominantes e, dentro de uma sociedade patriarcal, o ponto de vista histórico foi 
contado pela ótica masculina ${ }^{3}$.

Há de se considerar que ainda é relativamente inexpressiva a presença de mulheres, afrodescendentes e ameríndios como artistas, curadores e galeristas ou marchands, papéis mormente exercidos pelos detentores de poderes econômico e social. A teórica e crítica Gayatri Chakravorty Spivak coloca em pauta essas mesmas inquietações no artigo de 2010 Pode o subalterno falar?, considerado um texto de fundamental importância das questões sobre o pós-colonialismo, autora afirma que o subalterno não tem poder de fala e que, a "mulher" sob esta perspectiva, não teve seu devido valor respeitado na lista de prioridades globais. Spivak (2010, p.126) afirma que: “A representação não definhou. A mulher intelectual como uma intelectual tem uma tarefa circunscrita que ela não deve rejeitar com um floreio." Conjectura-se que as mulheres artistas têm um papel de fundamental importância em evidenciar seu posicionamento artístico de modo mais contundente e engajado possível. Esta responsabilidade é cada vez mais necessária dentro de um sistema que dá pouco, ou nenhum, poder de voz aos que não estejam enquadrados dentro da visão masculina, prioritariamente branca e heterossexual, sobre a sociedade, a cultura e a política. Ao ter consciência da responsabilidade em se levantar esta bandeira, a arte - que é um ato político, mesmo que não seja uma ação consciente - pode apontar para esses pontos nevrálgicos. É evidente que obras realizadas por mulheres, não são necessariamente feministas, contudo, é apenas deste lugar, ou seja, sob a ótica do feminino, que se pode falar sobre os incômodos e as ânsias pelas mudanças.

E o que se pode dizer sobre arte feminista feita na América Latina? Apesar das questões supracitadas serem pertinentes às condições femininas dentro de um contexto mundial, existem especificidades que concernem apenas às realidades sociais, culturais e econômicas dos países latino-americanos. Um dos pontos cruciais ao se desviar o olhar para a arte feminista desta região, diz respeito às marcantes situações políticas enfrentadas durante as ditaduras militares. De acordo com a pesquisadora Luana Saturnino Tvardovskas (2015), os movimentos feministas ganharam força apenas depois das quedas dos regimes autoritaristas,

\footnotetext{
${ }^{3}$ A respeito desse assunto Walter Benjamin em Thèses sur la Philosophie de l'Histoire, de 1940, desenvolveu um dos documentos mais importantes do pensamento revolucionário. Nele, Benjamin defendeu fundamentalmente escrever a história a contrapelo, ou seja, do ponto de vista dos vencidos - contra a tradição conformista do historicismo alemão, ou seja, aquele que estava em consonância com os vencedores. Obviamente que o uso da palavra "vencedor" não faz referência a qualquer tipo de luta ou guerra, mas sim à "luta de classes", na qual um dos campos, a classe dirigente, "não cessou de vencer" (Tese VII) os oprimidos - desde Spartacus, o gladiador rebelde, até o grupo Spartacus de Rosa de Luxemburgo, e desde o Imperium romano até o Tertium Imperium nazista. (LÖWY, 2002).
} 
mesmo que durante esses períodos tenha havido lampejos de ações, não resultaram em movimentos artísticos significativos. Havia, no entanto, grupos organizados de mulheres a favor da anistia, de melhorias das condições de vida e, até mesmo, alguns jornais de cunho feminista. Tvardovskas (2015, p. 65) pondera também sobre o mercado de arte brasileiro que, apesar de ocupar um lugar de destaque em âmbito internacional, não se pode ser comparado com Europa e Estados Unidos, "os temas feministas na arte sofrem aqui de raquitismo." Parece que as discussões chegaram amadurecidas nos países periféricos e, além disso, há uma considerável carência de literatura na língua portuguesa que poderia servir como referência para pesquisas com este enfoque. Contudo, foi depois da abertura lenta e gradual - a transposição do regime militar para o democrático, na segunda metade da década de 1980 - é que o movimento feminista começou a tomar corpo no Brasil. Mulheres que voltaram do exílio traziam em sua bagagem concepções do feminismo mais atuante, sobretudo europeu, e dinamizaram as relações sociais, tanto no âmbito privado quanto no público, atuando de forma mais contundente no cenário cultural e político, redefinindo suas possíveis sexualidades e gêneros. Foram criados, em 1985, a Delegacia da Mulher, em São Paulo e o Conselho Nacional dos Direitos da Mulher (BARROS, 2016). A partir dos anos de 1990, mesmo com a crise econômica que assolou o país com o Plano Collor, as mulheres artistas "passaram a interagir ainda mais fortemente na transformação do imaginário misógino, respondendo tanto à maior abertura cultural derivada do fim dos governos autoritários, como à crescente visibilidade e legitimidade alcançadas pelos movimentos feministas." (TVARDOVSKAS, 2015, p. 91-92). Fato a ser ponderado é que existia, e ainda existe, certa resistência das mulheres artistas brasileiras em se autonomearem "feministas", já que, inicialmente, havia uma conotação negativa em se categorizar desta forma: se por um lado, aos olhares da direita, o movimento feminista pareceria imoral e perigoso na época do militarismo, por outro lado, o movimento era tido como reformismo burguês aos olhos da esquerda. Ocorre também para muitas pessoas de ambos os sexos que, ser feminista, está diretamente relacionado com a necessidade em se caracterizar como não feminina (SARTI, 1988).

Até certo ponto é possível considerar que foi o que ocorreu com Celeida Tostes (Brasil, 1929 - 1995). Escultora e professora de cerâmica foi, antes de tudo isso, uma incansável pesquisadora e incentivadora das artes do fogo e do barro. Nascida no Rio de Janeiro e criada pelos avós em uma fazenda no interior do mesmo Estado, perdeu a mãe com quando tinha apenas 1 ano de idade. Sem a presença da figura maternal, Celeida acabou por buscá-la, em certa medida, em seu trabalho com a cerâmica por meio dos dez mil ovos, das milhares de vênus, das centenas de esferas úteros e de tantas outras ações agregadoras. $\mathrm{O}$ 
masculino, contemplado em suas dezenas de Sentinelas figuras gigantes e fálicas, fez o contraponto que mais se destacou. Os registros sobre Celeida contam mais sobre sua formação e trajetória acadêmica, artística e profissional, do que sobre sua vida pessoal. Formou-se em Artes na Escola Nacional de Belas Artes (1955) e como Professora de Desenho e de Didática Geral e Especial na Faculdade de Filosofia e frequentou o curso de Antropologia Cultural na Faculdade de Educação da Universidade Federal Fluminense (1973), todos no Rio de Janeiro. Entre 1958 e 1959 ganhou uma bolsa do governo norteamericano na University of Southern California e Highlands, no Novo México, onde ampliou seus conhecimentos em técnicas industriais de cerâmica. Posteriormente, em 1975, ganhou um bolsa do Consulado Britânico para estudar na School of Arts do Cardiff College, no País de Gales, onde se reunia artistas com experiências em reciclagens de materiais. Ministrou cursos de profissionalização na Penitenciária Feminina de Belo Horizonte, Minas Gerais em 1980. Desse período até sua morte, coordenou o Projeto Formação de Centros de Cerâmica Utilitária nas comunidades da periferia urbana Morro Chapéu Mangueira, no Rio de Janeiro. Foi professora na Escola de Artes Visuais do Parque Lage, UERJ desde 1975 e na Escola Nacional de Belas Artes, UFRJ, onde obteve o título de livre-docente em 1987. Sua atuação foi de grande e considerável influência para uma geração de artistas formados nessas universidades. Por triste ironia do destino, a artista foi acometida por um câncer de mama e morreu em plena atividade aos 66 anos (Costa 2003).

Não é difícil de entender que, por sua formação, a sua vocação de artista e de docente já estivesse traçada. Mas, apesar disso, suas metodologias eram pouco tradicionais e, com a mesma liberdade vivenciada em sua infância, passava aos seus alunos o estímulo necessário para se produzir e pensar arte. Celeida era agregadora e engajada com seu trabalho como mulher, artista, pesquisadora, ceramista, brasileira. Envolvia sempre grandes grupos de pessoas para desenvolver seus milhares de objetos. Ou mesmo para desenvolver trabalhos comunitários, que podiam ou não ter a ver com seu trabalho acadêmico. Foi o caso do Morro Chapéu Mangueira, onde ela construiu um barracão com os habitantes para resgatar o conhecimento ancestral das moradoras em se fazer panelas de barro. Na obra de Celeida vê-se entrega, dedicação, intensidade e paixão. Sua vida e obra se fundiram como um vidrado na cerâmica. Sua devoção aos seus alunos e aos seus projetos era plena e ela fazia com a mesma abnegação que a sociedade espera de uma mãe no seio familiar. Talvez, por não ter tido a presença da mãe em sua vida, tenha escolhido dedicar-se aos rebentos da arte e educação.

Nas séries Fendas e Ninhos (Figuras 1), Celeida explorou o conceito de nino como útero, primeira morada. A forma redonda das peças, dos potes, dos ovos reforçava o 
aconchego de um lugar sem arestas, sem pontas uma morada sem começo, meio e fim, um universo particular dentro de outro, como um cosmos sobreposto com formas redondas que se encaixam. Gesto Arcaico, os Amassadinhos (Figura 2) foi uma instalação apresentada na XXI Bienal de São Paulo formada por aproximadamente vinte mil peças de barro (argila não queimada) feitas pelo elementar gesto de apertá-los entre as mãos. Gesto Arcaico surgiu da necessidade em buscar uma espécie de linguagem visual coletiva unificada e individual (tal qual são as digitais de cada ser), surgem como índices de subjetivas e únicas impressões já que são feitas de gestos e cores (óxidos que pigmentam o barro) distintos. Sobre o trabalho a artista relatou:

Este foi o trabalho que apresentei na XXI Bienal de São Paulo / 1991. Trata-se de uma experiência feita com o toque das mãos. Para mim, no paleolítico superior, o nascimento das "Vênus", ao que se tem confirmação até agora, deu-se no bojo das mãos. Como se a mão fosse o ventre. Assim, o aperto reflexo da mão no material mole, que também é relação de magia, relação com o corpo da mulher, com a agricultura ou com a fartura, deu origem às Vênus. Eu estava fazendo muitas Vênus pequeninas e ferramentinhas. Então comecei a depurar o gesto, a ver que no simples amassado você coloca o olhar e arma uma história. O conjunto de peças que denominei de "Gesto Arcaico",é, na verdade uma coleção de apertos reflexos, realizados pelas mais diversas mãos ao encontrarem no seu bojo a matéria maleável da argila. Trabalhei com os mais diversos segmentos de nossa sociedade: foi feito no presídio da Frei Caneca, no Parque Lage, na Vila Rosali _ lugar das chamadas prostitutas, no Museu de Arte Moderna / RJ, com doutores da COPE da UFRJ, com gente de rua, com madames, com criancinhas pequenas, enfim, centenas de mãos se identificando num só gesto. Um mutirão sem referência de classe. (COSTA, 2006, p.75)

Com cuidado de quem repara nos detalhes e delicadezas das coisas, a artista inclui de modo participativo na criação da instalação aquelas pessoas que são de muitas formas excluídas da sociedade. Por meio das diferenças a Celeida congrega um conjunto que de longe parece homogêneo, mas que, ao se aproximar e andar por entre a grande roda centralizada ao centro do espaço, deflagra as diferenças e especificidades de cada ser que a formou e relembra de que todo o ser se origina a partir de um útero.
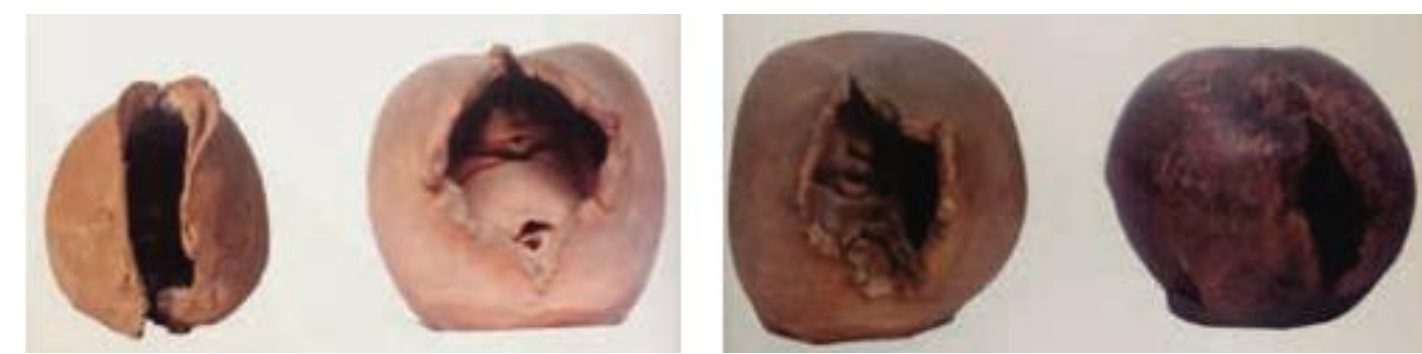

Figura 1. Celeida Tostes. Série Fendas, 1979. Cerâmica. Acervo Coleção Marimar e Henri Stahl. Disponível em: 


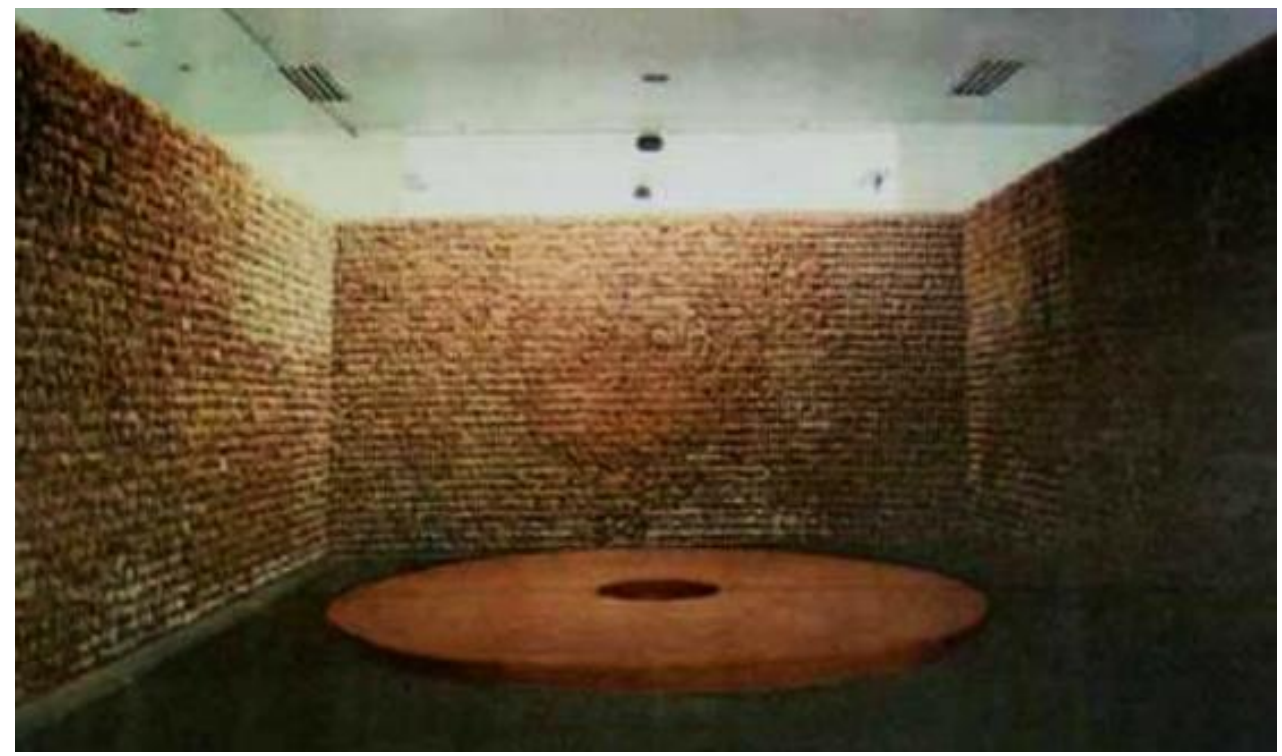

Figura 2. Celeida, Tostes. Gesto Arcaico, 1991. Disponível em:

https://repositorio.unesp.br/bitstream/handle/11449/86935/santos_er_me_ia.pdf?sequence=1\&isAllowed=y. Acesso em: 24 de abril de 2020 .

Um de seus trabalhos mais emblemáticos e significativos, inclusive para a própria artista, foi a performance Passagem (Figura 3), onde a artista integrou-se à mesma matéria com a qual ela produzia seus trabalhos artísticos. Nela Celeida despojou-se das roupas e vestiu-se de barro, adentrou em um grande pote de barro com auxílio de duas mulheres paramentadas de branco, e nele permaneceu em posição fetal até rompê-lo, rasgando suas paredes para, simbolicamente, renascer. Em uma poesia relato feita depois da ação, Celeida se viu como mineral, animal, vegetal. Se percebeu amorfa. O espaço ao seu redor transformou-se e encolheu. A acolheu. Em seguida, a artista foi cuidadosamente resguardada dentro de que se pode interpretar como uma urna funerária, possivelmente inspirada nos extintos povos originários brasileiros, Marajoaras e Tapajós da Amazônia, cujos os corpos de seus mortos eram enterrados em grandes urnas de cerâmica, detalhadamente adornadas com desenhos geométricos e formas antropomorfas ${ }^{4}$. Suas assistentes, assim como doulas em um processo de parto, utilizaram a técnica milenar do acordelado (tiras de argila afixadas de modo espiral para formar a parede do pote). Tudo ocorreu em um ambiente hermeticamente fechado e

\footnotetext{
${ }^{4}$ Ao enterrar os mortos em posição fetal em potes arredondados os povos originais ameríndios estavam, de forma simbólica, recolocando-os de volta ao útero da mãe primordial, a Pachamama, Gaia, a Grande Mãe ou Deusa da fertilidade
} 
seguro: seu apartamento na capital carioca transformou-se em um portal para esse ritual de vida-morte-vida. O chão foi coberto de terra e uma esteira de palha estava debaixo do poteútero para recebe-la com maior maciez do que a terra seca poderia oferecer.
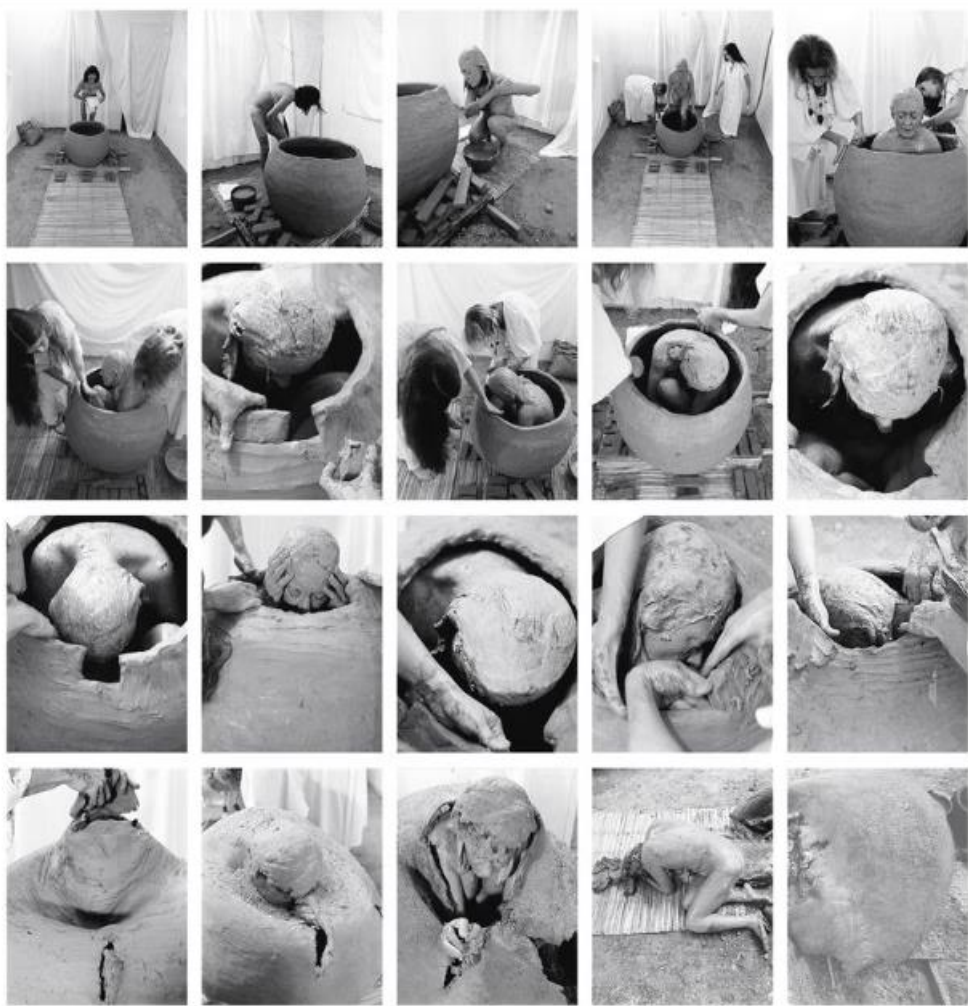

Figura 3. Celeida Tostes, Performance Passagem (Rio de Janeiro, Brasil), 1979. Fonte:

< https://hammer.ucla.edu/radical-women/art/art/passagem-passage> Consultado em: 12 jan. 2020

\author{
Despojei-me. \\ Cobri meu corpo de barro e fui. \\ Entrei no bojo do escuro, ventre da terra. \\ O tempo perdeu o sentido de tempo. \\ Cheguei ao amorfo. \\ Posso ter sido mineral, animal, vegetal. \\ Não sei o que fui. \\ Não sei onde estava. \\ Espaço. \\ A história não existia mais. \\ ons ressoavam. \\ Saíam de mim. \\ Dor. \\ Não sei por onde andei. \\ O escuro, os sons, a dor, se confundiam. \\ Transmutação. \\ O espaço encolheu. Saí. \\ Voltei. (PINTO 1994, pp. 92 e 93)
}

Há de se considerar que o contexto político e histórico em que a artista vivia era de grande repressão por conta da Ditadura Militar que países da América Latina passaram entre os anos de 1960 até 1980 aproximadamente. Concomitantemente, enquanto no Brasil havia 
um movimento de ruptura iniciado com o movimento Neoconcreto, no estrangeiro, a arte Povera, Body Art, Pós-Minimalismo, etc., eclodiam como movimentos artísticos de grandes quebras de paradigmas.

Foi com o seu próprio corpo, através da criação de objetos, ou com o uso direto deste, por meio da performance, que Celeida valorizou ao extremo a experiência do processo-barrocorpo. Ao se recriar e voltar desse estado quase inconsciente e transcendental, Celeida não apenas "se pari", como também abre uma passagem para parir a produção artística de tantas outras mulheres que, assim como ela, se recriam, se reinventam, se concebem, se "celeidam".

E como um ente que se autor reproduz, Kukuli Velarde (Peru, 1962) traz à tona de modo recorrente o autorretrato sob diversas formas em sua obra. A artista trabalha se utiliza não apenas da cerâmica para se expressar, como também da pintura, de desenhos, instalações, objetos, vídeo arte, entre outros suportes. A temática de sua obra gira em torno do erotismo, das mitologias religiosas, da sua latino-americanidade e, evidentemente, da sua autoimagem. Suas cerâmicas emprestam, com toda liberdade poética, a inspiração da arte pré-colombiana para criar figuras fantásticas que confrontam temas contemporâneos, como questões de gênero e identidade, além de suscitar algumas preocupações sociopolíticas. Seu corpo e rosto são sempre usados como ponto de partida, tanto para suas pecas, quanto para suas pinturas. De maneira sarcástica, Kukuli explora o seu corpo feminino, entrecruzando símbolos, gestos e elementos conhecidos na iconografia sacra, com imagens que se assemelham às mitologias da antiguidade clássica e às dos povos nativos do continente latino-americano. Na obra Sta Chingada: The Perfect Little Woman da série Cadáveres (Figura 4) a imagem em um primeiro lance de olhar não parece ser chocante, remete às tão familiarizadas imagens de santas católicas, onde o sofrimento é a condição para a redenção. Se "ser mãe é padecer do paraíso" Kukuli representa acidamente essa máxima: a mulher está em uma fase avançada da gestação; do seu seio direito jorra sangue ao invés de leite; além de amordaçada, ou seja, impossibilitada de falar, capaz apenas gemer e gritar, ela usa um cinto de castidade, objeto de tortura e controle feminino utilizado em larga escala na Europa Medieval; o seu coração de ouro reluzente está cravejado de espinhos e sangra sem parar, cadenciado com o sangue do peito; os anjinhos, que de angelicais têm apenas o olhar e as asas, são como cúmplices e apoiadores da mártir que tem ao seu redor uma cerca de arame farpado; nas figuras em detalhe, vê-se que um dos anjos retira a máscara de alegria que encobre a real cara de dor (ou seria êxtase?) que a santa sustenta; todos os cinco anjinhos possuem enormes falos, desproporcionais ao seu tamanho e contexto - mais uma cutucada da artista com relação à 
ideia da assexualidade dos anjos, descrita nas escrituras sagradas ${ }^{5}$. Como esposa, mãe e,

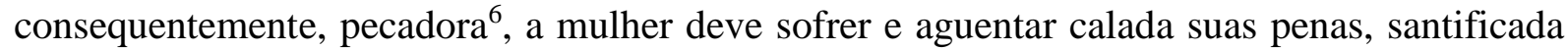
por seus atos de redenção. Quanto mais ela sofre, mais a bondade de seu coração é reconhecida e reverenciada. A “mulherzinha perfeita” é aquela que não é reativa, mas submissa, resiliente, suporta as aflições, as violações, as torturas físicas e psicológicas, com a placidez de uma santa.

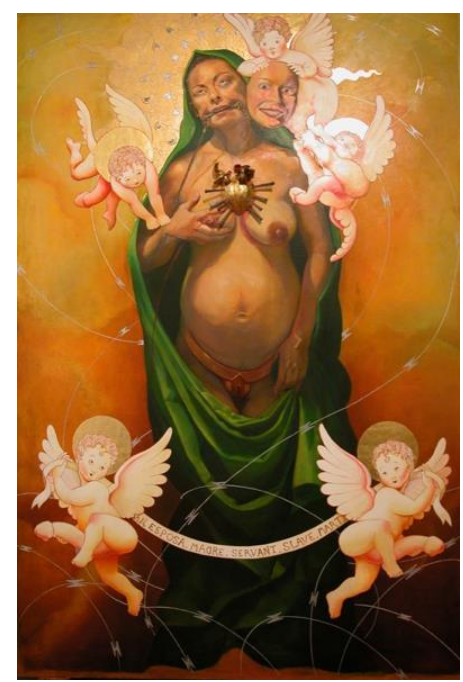

Figura 4. Sta Chingada: The Perfect Little Woman, série Cadáveres. 2005 Óleo e acrílica. 1,21 x 1,82 cm. Disponível em:

https://repositorio.unesp.br/bitstream/handle/11449/154847/almeida_fl_dr_ia.pdf?sequence=3\&isAllowed=y. Acesso em: 12 abril 2020

A obra Vênus? faz referência direta à pintura renascentista de Botticeli, O Nascimento de Vênus - obra possivelmente criada por encomenda para um membro da rica família Médici. O retrato da deusa do amor, chamada pelos gregos de Afrodite, sugere uma pose corporal tímida: a deusa encobre os seios e a genitália com suas mãos e longos cabelos. Por esta razão, ela é também conhecida como Vênus pudica. Inspirada no mito que dá nome à obra, é uma das poucas obras laicas feitas, ou que sobreviveram, da época. Em sua releitura da Vênus, Kukuli se coloca na mesma posição, porém omite os outros elementos da tela, coloca-se envolta a uma espécie de manto rendado, que emoldura delicadamente seu corpo. Suas feições, ao contrário da deusa de Botticelli, são ligeiramente tensas, não sugerem tranquilidade e espiritualidade. Apesar da semelhança da postura do corpo, sua anatomia parece ser mais real do que a Vênus original, que tem formas alongadas e caimentos

\footnotetext{
${ }^{5}$ Curioso observar que os anjos foram historicamente representados com pênis em dimensões diminutas, o que suscita dúvida sobre a neutralidade do sexo masculino, ou em outras palavras, o homem como parâmetro para tudo, já que o corpo feminino sugere sedução, mesmo sendo de uma criança.

${ }^{6}$ Sob a ótica das religiões judaico cristãs.
} 
impossíveis de serem reais. A cor de carne que surge ao fundo da renda reforça ainda mais sua conexão com a matéria, em detrimento da Vênus que quase parece flutuar na concha. Talvez seja por essa razão que o titulo da obra seja uma interrogação e não uma afirmação. Será que a representação feminina ainda se sustenta entre esses cânones? Quanto tempo ainda será preciso para que este eixo se desloque de lugar?

Kukuli escancara as inquietações que povoam o inconsciente das mulheres, a hipocrisia de uma sociedade onde as mulheres lutam para serem respeitadas. Em seus trabalhos escultóricos, feitos em série com moldes de gesso, utilizando a técnica da barbotina e modelagem, com aplicação de englobes coloridos, além de esmaltes e pinturas a frio, é que se consegue enxergar de modo mais evidente suas raízes culturais afloradas. A série Plunder $m e$, Baby (Figuras 5 a 7) destaca-se pela recuperação da técnica e elaboração iconográfica da arte das civilizações andinas (Cupisnique, Nazca, Mochica, Tiahuanaco) como mote para a representação do erotismo feminino em plena provocação social e ideológica. O título da série traduzido para o português seria algo parecido com "saquei-me" ou "roube-me" - palavra comumente utilizada nas pilhagens e saques que acontecem em guerras. Fica claro o engajamento político da artista ao criar uma série de objetos que aludem e se inspiram na cerâmica dos povos originários do continente americano. A crítica ao modo como essas culturas foram exploradas, roubadas, dizimadas, violadas, inferiorizadas, discriminadas, tratadas com tamanha indignidade como se não pertencessem à raça humana. A instalação consiste em dispor as peças em prateleiras, tal como ocorre em um museu antropológico: as peças seguem devidamente acondicionadas, enquanto os herdeiros dos criadores são ignorados, condenados por sua origem e condição socioeconômica. Os títulos de suas obras definem a percepção da peça escultural e convidam o espectador a refletir sobre o conceito de arte não ocidental e os preconceitos que nela estão contidos. Com títulos individuais que reforçam o escárnio presente em suas produções, Kukuli reserva um comentário elucidativo para cada uma. Em uma das obras ela comenta ${ }^{7}$ : "Nunca sei o que ela está pensando. Selvagem, simples, lasciva, muy caliente"; para outra, ela reserva o comentário: "Desobediente brincalhona. Não acredita em hierarquias, a filha de uma grande [...]" $\mathrm{O}$ cuidado atinge outras camadas interpretativas, já que ela informa a região e a suposta data da peça, tal qual um artefato arqueológico, coisa que pode até, para alguns desavisados, confundir sua real origem.

\footnotetext{
${ }^{7}$ Comentários da artista coletados diretamente em seu website: www.kukulivelarde.com - Acesso 18/11/2017
} 

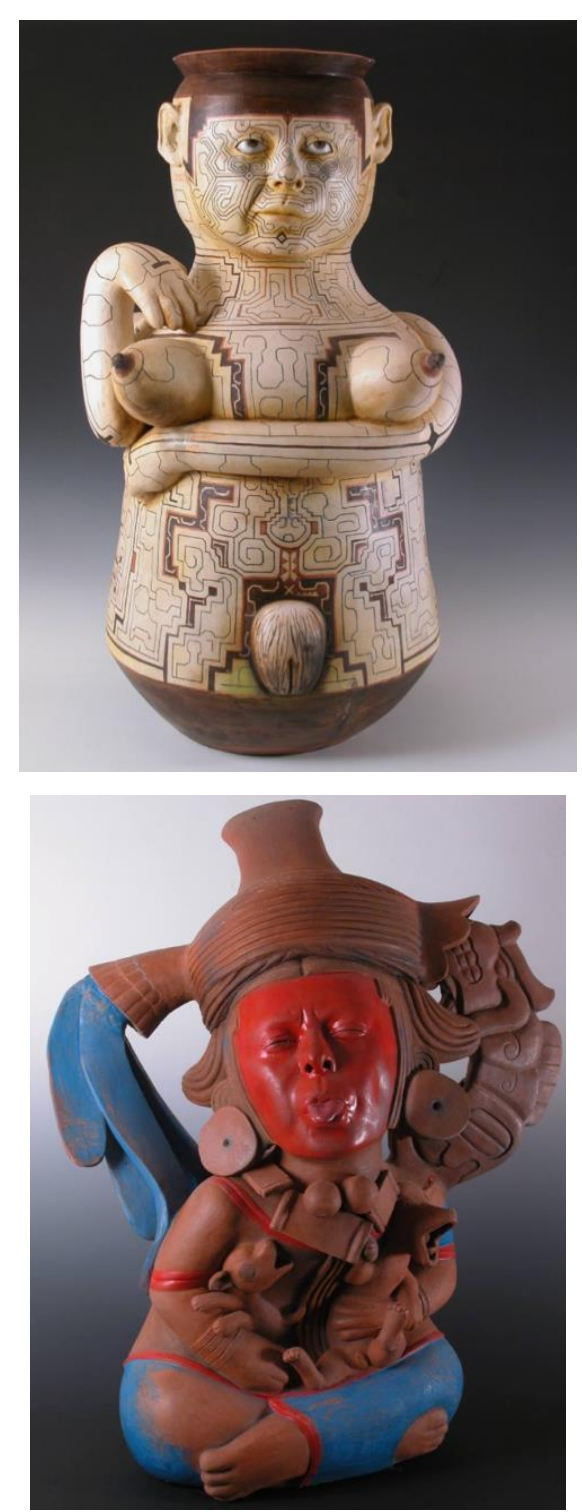

Figuras 5 e 6. Kukuli Velarde. Chuncha Cretina. Conibo AltoUcayali, Perú da série Plunder Me, Baby / Najallota Insolente. Maya México, 750 a.C. da série Plunder Me, Baby. 2007.Garth Clark Gallery. New York. Disponível em: https://repositorio.unesp.br/bitstream/handle/11449/154847/almeida_fl_dr_ia.pdf?sequence=3\&isAllowed=y. Acesso em: 12 abril 2020 
RELACult - Revista Latino-Americana de Estudos em Cultura e Sociedade

Revista Latinoamericana de Estudios en Cultura y Sociedad | Latin American Journal of Studies in Culture and Society V. 06, n⿳0 01, jan-abr., 2020, artigo no 1854 | claec.org/relacult |e-ISSN: 2525-7870

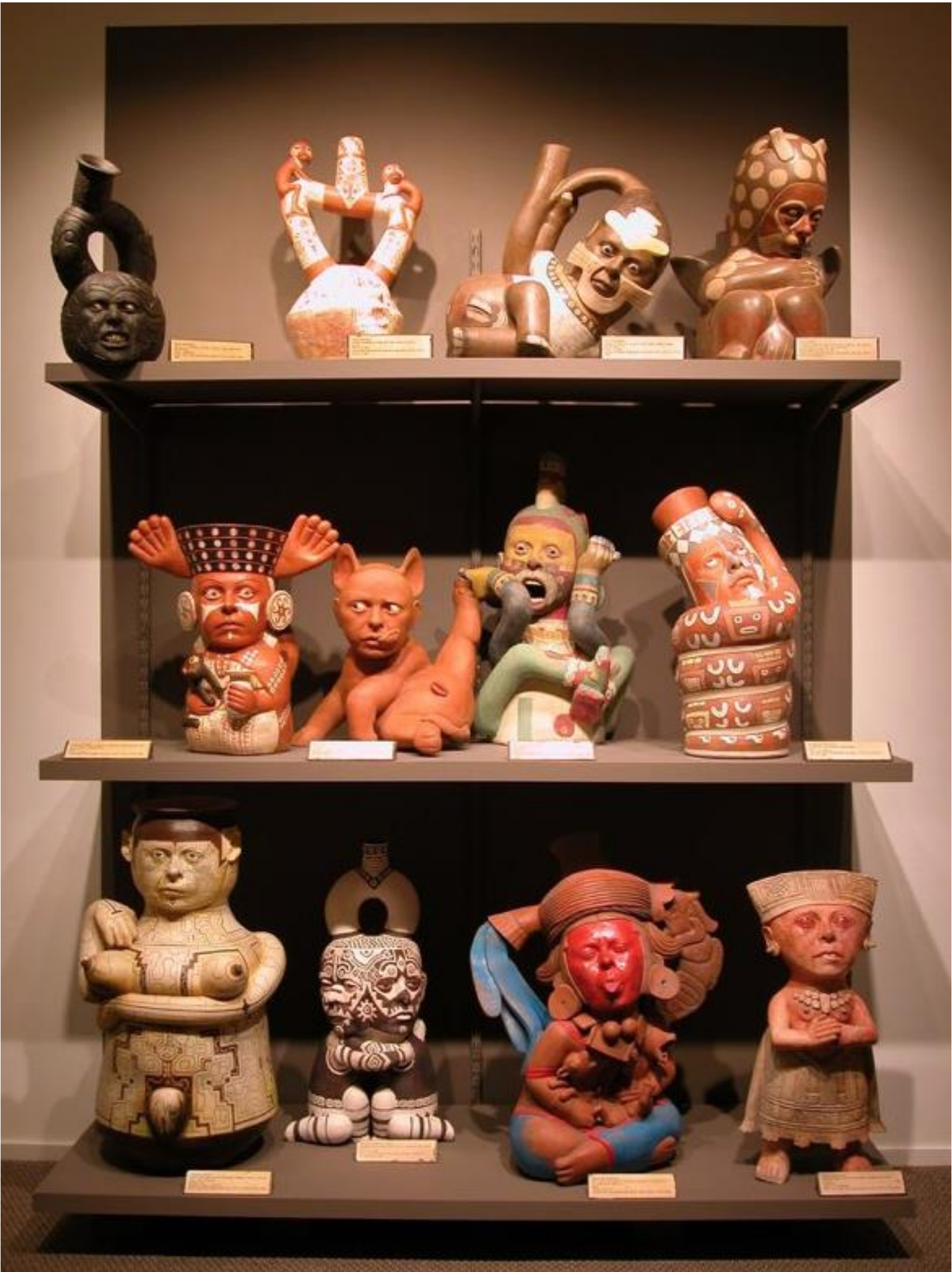

Figura 7. Kukuli Velarde. Plunder Me, Baby. 2007.Garth Clark Gallery. New York. Disponível em: https://repositorio.unesp.br/bitstream/handle/11449/154847/almeida_fl_dr_ia.pdf?sequence=3\&isAllowed=y. Acesso em: 12 abril 2020 
A série Isichapuitu (Figura 8), desenvolvida entre 1997 e 2002, foi criada a partir de uma única peça arqueológica mexicana datada com cerca de dois mil anos atrás. Como um exército de Budas, as peças foram dispostas no chão de modo a darem a impressão que avançam em direção de quem as mira: um jogo hipnótico, de quem tem os olhos fitos aos que lhes encaram de frente. Para montar a instalação a artista fez 36 reproduções das peças que, apesar de manterem o mesmo formato do corpo redondo com as mãos para cima, têm diferenciações específicas e exclusivas, feitas por meio de desenhos, pinturas e elementos agregados. Nelas, estão impressas as memórias, a ancestralidade, os desejos e os medos de sua criadora. Todas elas mantêm a fisionomia de Kukuli e permanecem com os braços para cima, como se suplicassem por ajuda. Mantêm a boca ligeiramente aberta, como se estivessem prestes a falar, mesmo que ainda lhe faltassem o sopro divino. Há uma aura de tensão presente nas figuras metamorfoseantes. Kukuli desconstrói aspectos relativos aos mitos populares ancestrais e atuais. Relativiza o corpo da mulher e o coloca em uma zona indefinida, um limbo de gêneros. Transcrevo a seguir tradução do texto da artista sobre série Isichapuitu ${ }^{8}$ :

Era uma vez um padre que amaldiçoou uma mulher que morreu. Em seu desespero, ele adquiriu um "navio da morte" por convocar o espírito e a amou uma vez mais. Manchaypuitu (masculino) e Isichapuitu (feminino). Os "cântaros de morte" eram basicamente vasos humanos, conhecidos por serem poderosas ferramentas capazes de trazerem de volta os espíritos do passado. Tradição oral, Cusco, Peru. Sinto meu corpo povoado por memórias, impressões, crenças, medos e desejos. Eles estão impressos profundamente, quase gravados. Eles me seguem, atormentando-me ou adoçando meu caminho. Nesta fase da minha vida, queria convocá-los, agradecerlhes e fazer a paz com cada um deles. Mas eu não sabia como, até eu ver uma fotografia de uma estátua mexicana da Rockefeller Collection no Metropolitan Museum, em Nova York. A figura tinha dois mil anos de idade e representava um filho masculino obeso com os braços erguidos. Alguém fez isso dois mil anos atrás e ainda, acredito eu, parecia-se comigo. Diz-se que toda obra de arte é um autorretrato. Imagino o artista Huastecan modelando a argila, dando os olhos dele, as bochechas cheias, a mandíbula superior saliente. Eu imagino que ele ou ela se pareça comigo, e então, eu me imagino fazendo a peça Huastecan há dois mil anos. Eu acredito que estou continuando com algo que comecei há muito tempo. Estou refazendo-me repetidamente, como se eu não quisesse afastar-me disso, como se fosse possível prolongar o momento da criação e continuar um eterno trabalho de amor. Isichapuitu é uma instalação de várias versões da mesma figura, mas cada uma responde a uma necessidade muito diferente. Varias vozes com suas próprias histórias: minhas histórias. Eles são órgãos diferentes de um único corpo apresentado no chão, um ao lado do outro, como uma metáfora da totalidade. Porque cada um de nós, somos todos a soma de vísceras e carne, expectativas e decepções, memórias e esquecimento, generosidades e mesquinhez. Eles seguem no chão porque eu quero que eles invadam o nosso reino. Eles estão um ao lado do outro, porque não foram

\footnotetext{
8 Tradução da autora. O texto original em inglês pode ser encontrado na íntegra no website da artista: http://www.kukulivelarde.com - Acesso 18/11/2017
} 
criados para serem observados e qualificados como objetos. Seu valor não reside nas minhas habilidades, mas na sua mera existência. Eles existem, primeiro para mim, e depois para todos. A instalação de Isichapuitu é um exorcismo, mas também é uma despedida e um novo começo. (VELARDE, 2002)

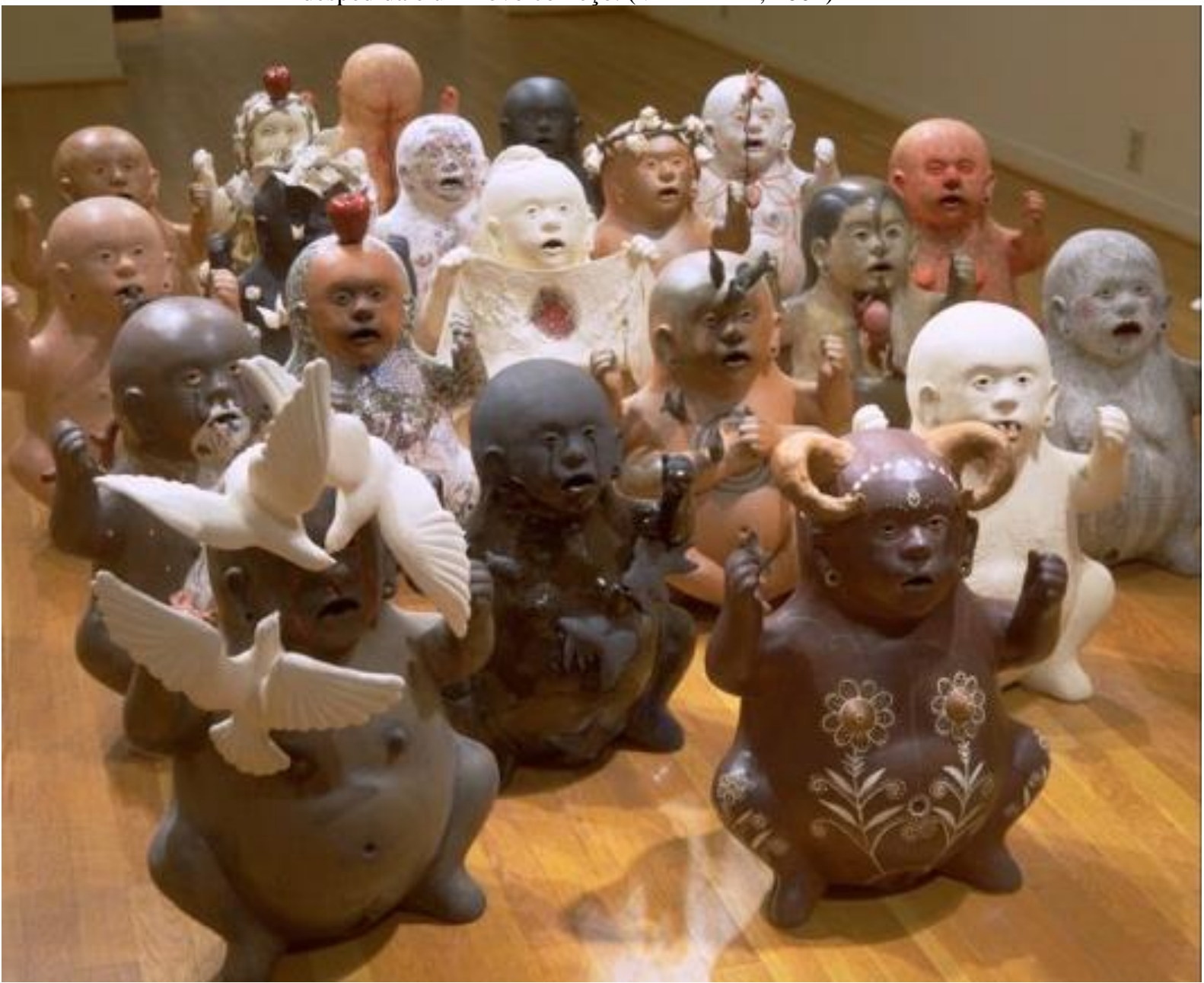

Figura 8. Kukuli Velarde. Isichapuitu. 1997-2002. Clay Studio. New York. Disponível em:

https://repositorio.unesp.br/bitstream/handle/11449/154847/almeida_fl_dr_ia.pdf?sequence=3\&isAllowed=y. Acesso em: 12 abril 2020

Com olhar crítico, mas sem perder a ternura, Kukuli tenta expurgar a densidade histórica dos antepassados do continente americano. Por meio de seus objetos autorrefenciais, a artista tenta reescrever o passado, se colocando no presente, como mulher artista ativista feminista e atuante.

Outra artista que faz também denuncia por meio da sua produção artística é Ruby Rumie (Colômbia, 1958). Por meio de diversos suportes, como pintura, escultura, fotografia, vídeo e instalação, Ruby aponta o dedo para a questão da violência contra as mulheres das regiões periféricas, mantendo um viés engajado em seu posicionamento artístico. A série intitulada Halito Divino (Figuras 9 a 11), exibida na Galeria Nohra Haime, em Nova York, foi desenvolvida por meio de uma vivência realizada com cem mulheres com idade entre $18 \mathrm{e}$ 
72 anos. Além, de serem todas originárias de Cartagena das Índias, cidade natal da artista, tinham outra semelhança em comum: em algum momento de suas vidas, foram vítimas de abuso dentro de suas próprias casas. Para executar o trabalho, Ruby solicitou que cada uma dessas mulheres soprasse, em um ato simbólico e ritualístico, dentro do respectivo pote suas mágoas, dores, tristezas, aflições, enfim, tudo aquilo que as fizessem lembrar dos momentos traumáticos. A escolha do tamanho do pote deveria ser proporcional ao trauma que elas haviam sofrido. Como um processo terapêutico, esta ação tinha a intenção de ajudá-las a se liberarem de todo padecimento sofrido e dar início a um processo de cicatrização. Em seguida, o pote foi selado, rubricado e um medalhão de metal preso à um cordão, foi colocado ao redor do pescoço da vasilha, como se fosse um colar em um busto. Nele estava contida a identificação da mulher que o soprou: as iniciais dos seus nomes completos e um perfil em silhueta. $\mathrm{O}$ fato não terem sido identificadas, conservou a privacidade e a integridade delas, mas, acima de tudo, operou como testemunho da invisibilidade e da indiferença encarada pela sociedade. A segunda parte do projeto consistiu na criação de outro painel, com a mesma quantidade de vasos, mas que fossem totalmente pintados de preto. Eles representavam o estágio de luto, tanto metafórico, quanto literal. A terceira e ultima etapa do trabalho consistiu em uma instalação com 32 vasos cerâmicos de tamanhos diferentes, cuja parte superior era coroada por delicadas peças de metal, representando corpos femininos - em alguns casos, eles eram banhados à ouro. Esse trabalho foi intitulado Crowned Vessel, literalmente, Vaso ou Recipiente Coroado. As coroas eram constituídas por pequeninas mulheres, que ora estavam juntas como uma ciranda, ora solitárias em cima dos vasos. Essas esculturas, feitas pelo processo de cera perdida, se assemelhavam aos amuletos que foram entregues às mulheres participantes, como símbolo da sua força e renascimento. Todas as fases do projeto Halito Divino tiveram mesas redondas interdisciplinares para discutir e refletir sobre a questão da violência contra as mulheres e, principalmente, escutá-las.

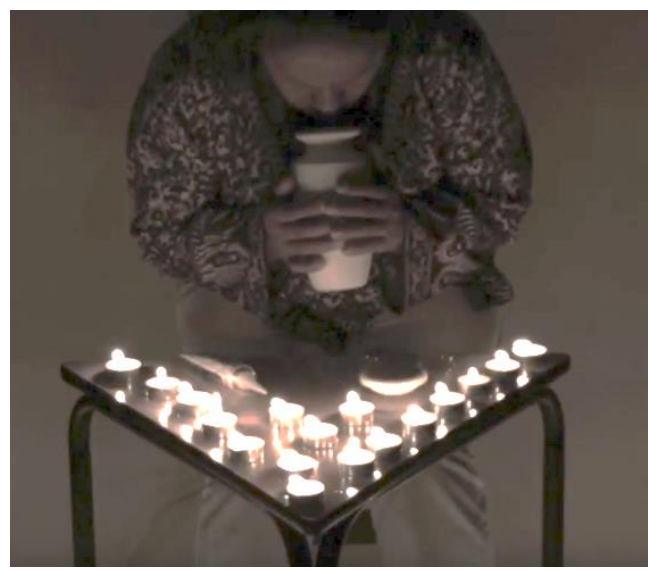

Figura 9. Ruby Rumie. Halito Divino - Ritual 2013-2014. Vídeo. 6 minutos. Galeria Nohra Haime, NY 
Disponível em:

https://repositorio.unesp.br/bitstream/handle/11449/154847/almeida_fl_dr_ia.pdf?sequence=3\&isAllowed=y. Acesso em: 12 abril 2020

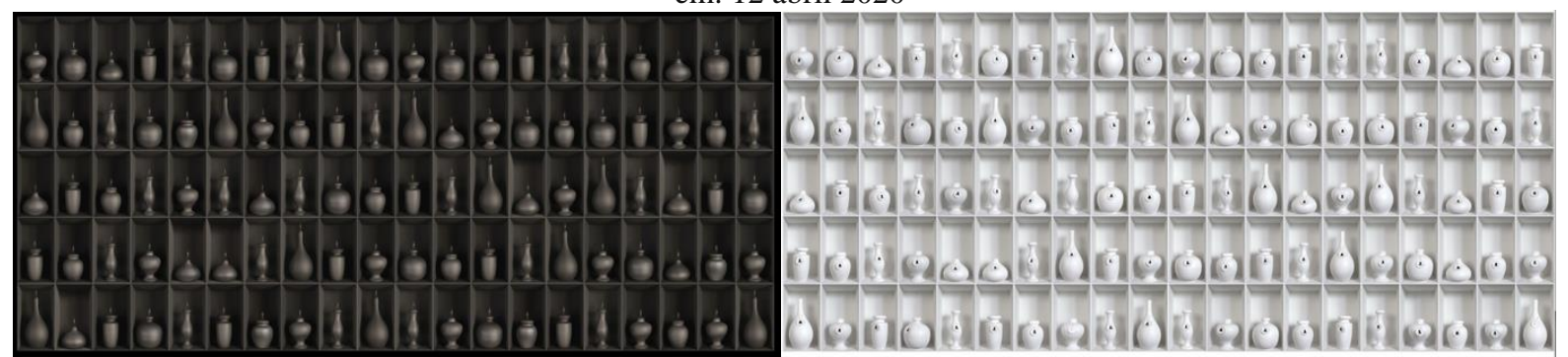

Figuras 10 e 11. Ruby Rumie. Halito Divino - Black and White Vessels. 2013. Cerâmica, madeira e metal. 190 x 440 cm. Galeria Nohra Haime, NY. Disponível em:

https://repositorio.unesp.br/bitstream/handle/11449/154847/almeida_fl_dr_ia.pdf?sequence=3\&isAllowed=y. Acesso em: 12 abril 2020

Cada homenageada representou "apenas" mais uma, dentre tantas que diariamente são agredidas no seio familiar - especialmente dentro do contexto social latino-americano. Tal qual os rituais de enterro praticados pelos ancestrais povos pré-colombianos, os sofrimentos encapsulados estavam, agora, para sempre sepultados em coroados potes cerâmicos, dispostos como um troféu - um triunfo para as mulheres. Em continuidade e prosseguimento à sua pesquisa, a artista elaborou uma grande instalação para dar voz e homenagear as vendedoras ambulantes de seu país, conhecidas como palenqueras: afrodescendentes que mantém a tradição do palenque, a língua criolla da Colômbia. Em uma performance ritualística, 30 mulheres na casa dos 70 anos, vestidas de branco, sentadas e enfileiradas, sob um tapete vermelho, têm seus pés lavados e "feitos" por diversas pedicures: uma para cada mulher. O local da ação era um salão de uma mansão colonial abandonada em Cartagena. Diariamente, por décadas, essas mulheres ganharam a vida vendendo alimentos em bacias de ágata, equilibrando-as em suas cabeças, pelas ruas da cidade. Costume dos antepassados era o de comentar que, ao caminharem de modo ziguezagueante, elas estavam "tecendo rua" - nome, inclusive, dado ao trabalho: Tejiendo Calle (Figura 12). Matriarcas de uma linhagem ancestral dos que, no passado colonial foram escravizados, ainda hoje compõem o quadro dos subempregos, como serviçais, lavadeiras, cozinheiras, babás, antigas amas de leite. Ruby, como uma mulher branca que teve uma criação e formação privilegiadas, tem consciência deste distanciamento: com respeito registrou cada participante do projeto, de modo a tentar resgatar a memória de seus antecessores, dignificando-as por meio de um trabalho de escuta ético, poético e estético. Este projeto as retratou sobriamente de branco, de modo diferente dos vestidos rodados e coloridos que elas usam para chamar a atenção dos turistas. Tornaram- 
se assim, protagonistas da ação ${ }^{9}$. A instalação traz, além da exposição fotográfica de retratos das mulheres, o vídeo da performance do ritual de lavagem dos pés, um conjunto de selos e quatro volumes de livros com fotos documentais da vida das palenqueras, denominado Halito Divino Corpus I, II, III e IV. Criar empatia, estimular a reflexão, desvelar os problemas como a violência de gênero, gentrificação, discriminação, estratificação social são temas que surgem de forma massiva em seus trabalhos. Ruby é uma artista que atua em muitas vertentes plásticas. As duas séries apresentadas possuem uma coerência poéticas inegável e complementar.

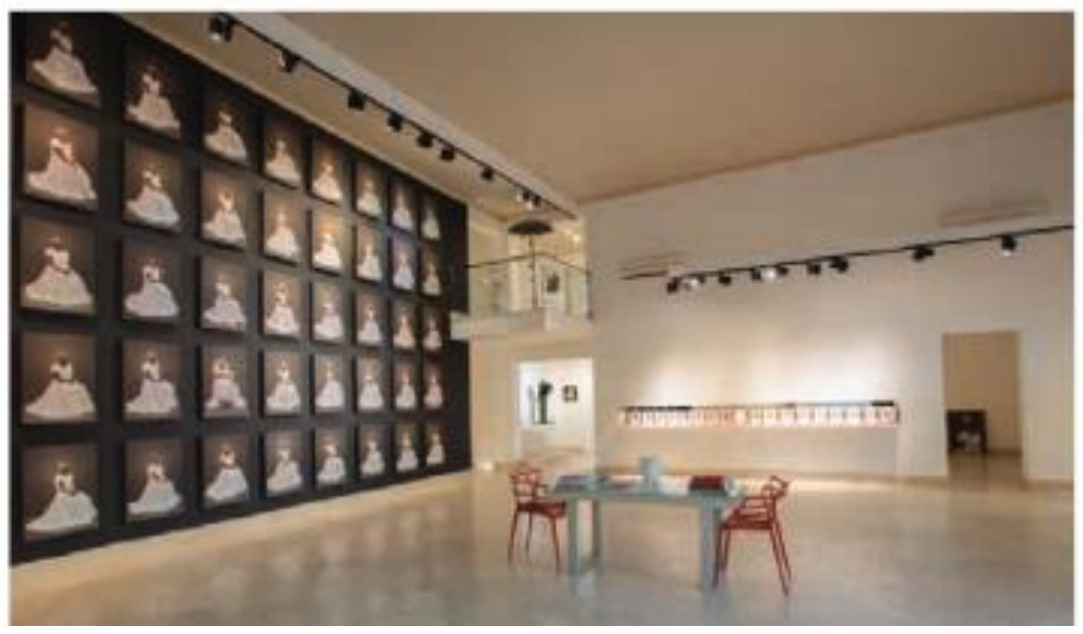

Figura 12. Ruby Rumie. Tejendo Calle, 2016. Vista geral da exposição na Galeria Nohra Haime, NY Disponível em:

https://repositorio.unesp.br/bitstream/handle/11449/154847/almeida_fl_dr_ia.pdf?sequence=3\&isAllowed=y. Acesso em: 12 abril 2020

Este artigo procurou, portanto, tangenciar um diálogo de modo poético entre as produções de três mulheres artistas latino-americanas, evidenciando pontos em comum que extrapolam a esfera do simples fato de serem de suas origens semelhantes e de tratarem de temas que perpassam o âmbito do feminino e, consequentemente, de uma poética embasada em conteúdos feministas, engajados em contextos sociopolítico e econômico. As três mulheres por meio da cerâmica, sobretudo, expressaram seus incômodos, suas inquietudes,

\footnotetext{
${ }^{9}$ Durante a pesquisa não foi possível descobrir de que maneira se deu a relação entre as palenqueras e a artista: uma mulher branca de feições europeias, com poder aquisitivo e status artístico consolidado. Na publicação videográfica, a artista descreve sua trajetória e mostra os bastidores dos projetos Halito Divino e Tejiendo Calles, onde é possível perceber seu pleno envolvimento e comprometimento com as mulheres. O vídeo encontra-se disponível em: https://www. youtube.com/watch?v=3QyrRKow92M - Acesso: 15/12/2017.
} 
suas angustias por serem artistas latino-americanas que não apenas observam, mas, são protagonistas do ato performativo de serem mulheres. Outro traço em comum à produção dessas artistas é o fato de trabalharem com objetos seriados, repetidos, multiplicados que enfatizam o motivo pelo qual a mensagem deva ser entendida, se não, ao menos reforçada para que não seja esquecida (como muitas mulheres foram e ainda o são). Celeida e Ruby trabalharam ativamente com mulheres para desenvolverem alguns de seus trabalhos que prescindiam a presença do "outro" (no caso, de "outras") para serem executados. Kukuli sustenta simbolicamente esse coletivo por meio das formas distintas e, contraditoriamente ao mesmo tempo, similares de suas peças cerâmicas - e não seriam justamente essas as particularidades mais significativas do que se pode afirmar de "uma identidade latina"?

O que se assinala finalmente como questão urgente e excruciante é a necessidade de haver mais pesquisas na área de artes visuais que patenteiam e validam as produções artísticas feitas por mulheres latino-americanas e que tenham como suporte a cerâmica, material carregado de estigmas e conceitos arcaicos. É imperativo atestar os devidos méritos por meio de pesquisas acadêmicas que legitimam a importância e a relevância da atuação e reconhecimento dessas artistas no campo das artes visuais e, especialmente, da arte contemporânea. Assim, as generalizações devem ser evitadas e, cada vez mais, camadas deste véu que encobre as Américas e suas artes precisam ser extirpadas. Estas artistas ativistas são a metáfora emblemática do famigerado eldorado latino-americano: enredam poeticamente a pluralidade das nações das quais são oriundos e bradam aos quatro cantos cartográficos que são 300 , são $350{ }^{10}$

\section{Referências}

ALMEIDA, Flavia Leme. Desvios do Barro: raízes culturais, feminismo e rituais nas poéticas de mulheres artistas da cena contemporânea latino-americana. Tese doutorado. Disponível em: https://repositorio.unesp.br/handle/11449/154847. Acesso em: 12 de abril 2020

ANDRADE, Mário de. Poesias Completas. São Paulo, SP. Martins Editora, 1955

BARROS, Roberta. Elogio ao toque ou como falar de arte feminista à brasileira. Relacionarte Marketing e Produções Culturais Ltda. Rio de Janeiro, RJ, 2016.

\footnotetext{
${ }^{10}$ A citação refere-se ao poema de Mário de Andrade Eu sou trezentos, contido no livro Poesias Completas de 1955. Nesta poesia, observa-se não apenas a experimentação estética do Modernismo, mas a ideia de multiplicidade cultural do povo brasileiro e, consequentemente, dos latinos americanos que mesclavam em suas raízes culturais influências internacionais e regionais e perseguiam um ideal universalista. (ANDRADE, 1955. p. 221.)
} 
BEAUVOIR, Simone. O segundo sexo. Editora Nova Fronteira, Rio de Janeiro, RJ, 2016.

Celeida Tostes. In: ENCICLOPÉDIA Itaú Cultural de Arte e Cultura Brasileiras. São Paulo: Itaú Cultural, 2020. <http://enciclopedia.itaucultural.org.br/pessoa21759/celeida-tostes>. Consultado em: 12 de Jan. 2020. Verbete da Enciclopédia. ISBN: 978-85-7979-060-7

COSTA, Marcus de Lontra. Arte do fogo, do sal e da paixão - Celeida Tostes. Rio de Janeiro: $C C B B, 2003$.

DUBY, Georges e PERROT, Michelle (Organização). História das Mulheres no Ocidente. Edições Afrontamento, São Paulo, SP, 1991.

GALEANO, Eduardo. Revista do Memorial da América Latina, São Paulo, SP, 2015

GARCIA, Carla Cristina. Breve História do Feminismo. São Paulo, SP : Claridade, 2015.

LÖWY, Michael. A filosofia da história de Walter Benjamin. Estudos Avançados da USP. Volume 16. Numero: 45. São Paulo: May/Aug, 2002. Disponível em: http://www.scielo.br/scielo.php?script=sci_arttext\&pid=S0103-40142002000200013\#not10 Acesso: 26/07/2017

PAZ, Octavio. O uso e a contemplação. In: V. V. A. A. História geral da arte: artes decorativas I. Madri: Ediciones del Prado. ISBN 84-7838-660-2 (1996)

PINTO, Regina Célia. Celeida Tostes. Rio de Janeiro: Museu do Essencial e do além disso, 2006, p. 92. Disponível em: http://elo-repository.org/museum-of-theessential/museu/library_pdf/celeida_tostes.pdf. Acesso em: 15 de abril de 2020.

SANTOS, Elaine Regina. Celeida Tostes: o barro como elemento integrativo na Arte Contemporânea. Dissertação de Mestrado. Disponível em: https://repositorio.unesp.br/bitstream/handle/11449/86935/santos_er_me_ia.pdf?sequence=1 \&isAllowed=y Acesso em 24 de abril de 2020

SARTI, Cynthia. Feminismo no Brasil: uma trajetória particular. Cadernos de Pesquisa (Fundação Carlos Chagas), n. 64 fev. 1988, p. 38-47 // 1988

SERRA, Monica Allende e ESCOBAR, Tício (Organização). A diversidade como direito cultural. In Desenvolvimento cultural e desenvolvimento urbano. São Paulo, SP : Iluminuras, 2005.

SPIVAK, Gayatri Chakravorty. Pode o subalterno falar? Belo Horizonte, BH : Editora UFMG, 2010.

TVARDOVSKAS, Luana Saturnino. Dramatização dos corpos. Arte Contemporânea e crítica feminista no Brasil e na Argentina. Editora Intermeios, São Paulo, SP, 2015. 